\title{
A ressurreição corporal na tradição paulina: O sôma psychikón e o sôma pneumatikón
}

\author{
Dionísio Oliveira Soares
}

\section{Introdução}

A presente comunicação tem como temática o desenvolvimento da idéia da ressurreição corporal dentro da tradição paulina, especialmente em 1 Ts 4,13-18 e 2Co 15, tradição esta que, em relação ao tema, talvez seja mais antiga que a sinótica. A preocupação do apóstolo parece não tangenciar o reino messiânico material, humano, mas sim o escatológico.

Para tanto, serão analisados os textos acima citados, observando-se possíveis relações com o helenismo platônico e com a antropologia judaica, bem como possível tensão na concepção de homem presente na antropologia paulina: a relação entre o corpo físico (sôma psychikón) e o corpo espiritual (sôma pneumatikón). Por fím, não se pode deixar de mencionar como tal expectativa foi assimilada pelo cristianismo nascente.

\section{A ressurreição no cristianismo primitivo}

As concepções acerca do pós-morte no judaísmo do século I d.C. não eram homogêneas, como não era o próprio judaísmo de uma forma geral. Havia tendências diversas e conflitantes. Anteriormente, já no período do judaísmo pós-exílico tardio, as concepções do pós-morte haviam sido modificadas. O contato com as concepções gregas e persas já havia se dado. Com os gregos encontra-se o conceito de imortalidade de alma (grupos filosóficos e religiosos gregos discutiam e aperfeiçoavam aspectos referen- 
tes a essa temática) ${ }^{1}$; com os persas, a noção de ressurreição, juízo final e outras noções de cunho escatológico ${ }^{2}$. Em relação a esses últimos, uma hipótese provável é que o contato tenha se dado por ocasião do exílio, com a posterior influência de Ciro II e seus sucessores; outra hipótese seria o contato com a cultura persa no pós-exílio já como substrato cultural no Império Macedônio. Conforme já verificado neste trabalho, antes da época persa (VI século a.C.) não se encontra evidência de uma nova elaboração nesses conceitos a partir de influências estrangeiras. Este intercurso com as culturas predominantes resultou em novas expectativas relacionadas a crenças antigas, refletindo tais elaborações no judaísmo e, posteriormente, no cristianismo ${ }^{3}$.

Podemos concluir também que as duas hipóteses acima citadas não são excludentes, e uma parcela imensurável de cada uma contribuiu significativamente para as mudanças na escatologia judaica pós-exílica; essas mudanças levarão a duas formas distintas de expectativas e esperanças relacionadas ao futuro no cristianismo primitivo: uma a que chamaremos simbolicamente de "histórica" e outra que denominaremos, também simbolicamente, de "escatológica".

No Novo Testamento, a idéia da ressurreição possui mais de uma tradição; "as concepções são flácidas, como no judaísmo"4. Hagner assevera que a disjunção entre as narrativas de ressurreição no NT é uma conseqüência lógica da dificuldade de compreensão do fato por parte dos discí-

\footnotetext{
${ }^{1} \mathrm{Cf}$. as expressões em conformidade com a idéia grega de imortalidade da alma em 4Esd 7,75-101 (do I século d.C.), 4Mc 9,21-22 (também do I século d.C.) e Sb 3,1-4 (mais antigo, I século a.C.). Em 4Mc 17 a teologia do martírio necessário para salvar a nação do opressor com posterior recompensa aos justos é enfatizada. No texto de Sb 3,4 a última palavra do verso é athanasia (imortalidade), inusitada no Primeiro Testamento: "Aos olhos humanos pareciam cumprir uma pena (os mortos), mas sua esperança estava cheia de imortalidade". Em 8,13 ela é usada com o sentido de imortalidade pela lembrança, tema caro às civilizações antigas. Em 1,4, trata-se da imortalidade da alma como recompensa pela justiça de Deus.

${ }^{2}$ Cf. as noções escatológicas persas que teriam influenciado a apocalíptica judaica em RUSSELL, D. S. The Method and Message of Jewish Apocalyptic, p. 19, e em SHAKED, Shaul. Iranian Influence on Judaism: First Century B.C.E. to Second Century C.E. In: DAVIES, W. D.; FINKELSTEIN, Louis (Ed.). The Cambridge History of Judaism: Introduction; the Persian Period, p. 314. Entre essas noções esta a idéia da ressurreição corporal. Para uma visão geral da escatologia do Avesta, cf. MÜLLER, Friedrich Max. The Eschatology of the Avesta. In: Theosophy or Psychological Religion, p. 177-207.

${ }^{3}$ Cf. SEGAL, Alan F. Life after Death: a History of the Afterlife in the Religious of the West, p. 351-353.

${ }^{4}$ OEPKE, Albrecht. Resurrection in the NT. In: KITTEL, Gerhard; FRIEDRICH, Gerhard (Ed.). Theological Dictionary of the New Testament I, p. 371. O judaísmo a que o autor se refere é o do período pós-exílico tardio.
} 
pulos $^{5}$. A própria noção de "ressurreição" no NT, como na apocalíptica judaica, não aparece relacionada somente a um evento futuro, a uma ressurreição geral (Mt 22,28; 25,31-46; Jo 11,24; Ap 20,11-15), mas também a uma "primeira" ressurreição específica dos justos antes do fim (Mt 27,52; Lc 14,14), dos que já estão "mortos em Cristo" (1Ts 4,16). Nas cartas paulinas não se menciona a ressurreição dos ímpios; já as epístolas universais não mencionam qualquer ressurreição, seja de justos ou de ímpios.

Uma das tradições presentes no NT é a do túmulo vazio, considerada uma tentativa de amenizar um grande problema para o cristianismo primitivo: o fato de, concretamente, ninguém ter testemunhado a ressurreição de Jesus, pelo menos nenhum dos escritores neotestamentários. Rudolf Bultmann, referindo-se a Mc 16,1-8, texto que narra a primeira atestação do túmulo vazio, efetuada pelas mulheres, afirma tratar-se de uma "legenda apologética", a qual pretende "provar a realidade da ressurreição de Jesus pelo túmulo vazio", fazendo parte de um estágio tardio das tradições pascais.

Essa tradição ajudava também a superar outro problema: a crença em fantasmas e espíritos já era quase universal na cultura popular, de forma que descrever Jesus simplesmente como um espírito era o mesmo que equipará-lo a um fantasma.

Por outro lado, pesa também o fato de que, com a predominância da doutrina grega acerca da imortalidade da alma, corria-se o risco de se assumir que somente a alma imortal de Jesus teria sobrevivido à sua morte, $\mathrm{o}$ que significaria dizer que sua morte foi igual a dos demais mortais.

Em Mateus 27 e 28 a polêmica judaico-cristã se torna clara: os judeus aparecem solicitando a Pilatos que colocasse guardas no túmulo para que o corpo de Jesus não fosse roubado pelos discípulos (Mt 27,62-66) e, posteriormente, subornando esses guardas romanos para afirmarem que o corpo do Cristo tinha sido roubado pelos próprios discípulos (Mt 28,1115), fato que inviabilizaria a tradição do túmulo vazio como prova cabal da ressurreição. Esses episódios não aparecem nos outros sinóticos e nem no evangelho joanino. Pela narrativa mateana, a forma de dissipar a dúvida entre os judeus que não criam na ressurreição (dissipando também o surgimento da mesma dúvida entre os cristãos) seria atribuir àquele grupo de fraudadores a culpa pela existência dessa dúvida, ou seja, trata-se de des-

\footnotetext{
${ }^{5}$ HAGNER, Donald. Gospel, Kingdom and Resurrection in the Synoptic Gospels. In: LONGENECKER, Richard N. (Ed.). Life in the Face of Death: the Resurrection Message of the New Testament, p. 99-121.

${ }^{6}$ BULTMANN, Rudolf. A History of the Synoptic Tradition, p. 314.

${ }^{7}$ Ibidem, p. 311.
} 
qualificar a possibilidade da dúvida e ratificar a tradição do túmulo vazio ${ }^{8}$. A explicitação do evangelista da presença dos guardas junto ao túmulo exclui totalmente a hipótese de furto, atribuindo esta idéia a uma invenção maldosa das autoridades judaicas ${ }^{9}$. Esses textos do evangelho de Mateus "pertencem a uma fase da tradição que reflete uma atitude apologética dos cristãos frente às asserções dos judeus de que os discípulos de Jesus haviam roubado seu corpo"10.

Dentro da tradição sinótica, Lucas deixa claro a ressurreição corpórea de Jesus: este não somente pede para que os discípulos toquem em seu corpo físico, mas também pede comida e a come diante deles (Lc 24,3643); seus leitores eram, em grande parte, helênicos (negavam a ressurreição do corpo). Reiterando essa posição, o Evangelho de João faz questão de não deixar dúvidas quanto à ressurreição física de Jesus: trata-se de uma ressurreição corpórea e física ${ }^{11}$; a escola joanina polemiza freqüentemente com o gnosticismo. João apresenta também uma novidade em relação à ressurreição dos fiéis na tradição sinótica: não é Deus quem os ressuscitará, mas sim o próprio Jesus, como demonstração de seu poder, que os ressuscitará no último dia $(\text { Jo } 6,40.44)^{12}$.

Quanto aos adversários de Jesus, os Sinóticos e Atos revelam a diferença entre Saduceus e Fariseus quanto à ressurreição ${ }^{13}$. Ao passo que os primeiros, por aceitarem somente a Torá escrita como paradigma, não aceitavam a ressurreição, é dito que os fariseus a aceitavam, certamente não nos moldes apregoados por Cristo. Flávio Josefo testemunha que "eles [os fariseus] acreditam que as almas têm o poder de sobreviver à morte e que existem recompensas e punições sob a terra para aqueles que viveram na virtude ou no vício: prisão eterna é a sorte das almas ruins, enquanto as almas boas recebem uma passagem fácil para uma nova vida" ${ }^{\prime 4}$. Josefo também parece expressar sua própria opinião:

\footnotetext{
${ }^{8}$ Mt 28,15: "Então eles, tendo recebido o dinheiro, fizeram como foram instruídos. E essa história tem-se divulgado entre os judeus até o dia de hoje".

${ }^{9}$ JEREMIAS, Joachim. Teologia do Novo Testamento, p. 430.

${ }^{10}$ GROSSOUW, W. Verbete Ressurreição de Jesus Cristo. In: VAN DEN BORN, A. (Ed.). Dicionário enciclopédico da Bíblia, p. 1310.

${ }^{11}$ Jo 20,27: "Depois disse a Tomé: Chega aqui o teu dedo, e vê as minhas mãos; chega a tua mão, e mete-a no meu lado; e não mais sejas incrédulo, mas crente".

${ }^{12}$ Cf. SEGAL, Alan F. Life after Death: a History of the Afterlife in the Religious of the West, p. 457. Segundo este autor, nesse trecho o evangelista faz a conexão entre a ressurreição e a eucaristia.

${ }_{14}^{13}$ Mt 22,23-33 par.; At. 23,6-10.

14 JOSEPHUS. Jewish Antiquities, 18.4. Harvard: Harvard University Press. Edição da Loeb Classical Library.
} 
Não sabeis que aqueles que deixam a vida em conformidade com as leis da natureza e pagam o empréstimo recebido de Deus, quando ele que emprestou achar por bem cobrar, obtêm reconhecimento eterno; suas casas e famílias estão seguras, suas almas, imaculadas e obedientes, recebem os lugares mais santos no Céu, de onde, na revolução dos tempos, retornarão para encontrar nova habitação em corpos castos $?^{15}$

Essa concepção poderia representar a ressurreição como uma espécie de reencarnação; entretanto, tal idéia não encontra recepção nos textos da Escritura Hebraica, sendo muito improvável que Josefo pensasse nestes termos. Sua idéia parece se alinhar mais na perspectiva apocalíptica já presente em Dn 12, com as promessas de recompensa ou punição eterna num corpo físico ressuscitado.

Um aspecto digno de nota é que as idéias de ressurreição estiveram presentes nas camadas populares da sociedade judaica, e o movimento de Jesus era influente nesses redutos. A convicção da ressurreição permitiu a esses grupos uma articulação a partir da definição de sua identidade. Assim, a ressurreição torna-se uma espécie de símbolo que condensa uma visão de mundo, traça limites e constrói comunidades ${ }^{16}$. Neste sentido simbólico, a ressurreição corporal pode ser uma idéia utilizada para identificar determinados grupos ${ }^{17}$.

A expectativa cristã reflete ainda um desejo por vida eterna antigo, o qual perpassa todo o Novo Testamento, sempre em relação aos justos. A influência grega pode ser percebida, especialmente no que tange a uma adaptação da perspectiva helenística sobre o destino do homem no pósmorte: mesmo se em alguns círculos do cristianismo primitivo se ignorasse a idéia de uma alma que sobrevive à morte, pensava-se numa imortalizarão futura, alcançada através da ressurreição em um corpo transformado e uma posterior ascensão aos céus ${ }^{18}$, como no caso da tradição paulina.

\footnotetext{
${ }^{15}$ Idem. The Jewish War, 3.374. Harvard, Loeb Classical Library.

${ }^{16}$ SETZER, Claudia. Resurrection of the Dead as Symbol and Strategy. In: Journal of the American Academy of Religion 69.1, 2001, p. 65-66.

${ }^{17}$ Idem. Resurrection of the Body in Early Judaism and Early Christianity: Doctrine, Community and Self-Definition, p. 93. No segundo capítulo dessa obra, a autora analisa a idéia da ressurreição entre os primeiros seguidores de Jesus, incluindo entre esses os de Corinto. No quinto capítulo, a autora discute a importância da crença na ressurreição em termos da definição da comunidade sobre si mesma, incluindo nessa análise as inscrições funerárias.

${ }^{18}$ SEGAL, Alan. Heavenly Ascent in Hellenistic Judaism, Early Christianity and their Environment. In: ANRW II.23.2, 1980, p. 1333-1394.
} 
Alguns textos no Novo Testamento sugerem ainda a ascensão imediata do fiel após a morte ${ }^{19}$, o que pode indicar que alguns escritores do NT estavam pensando sobre a questão do lugar onde os mortos passariam o período interregno de morte e ressurreição final. Nos escritos paulinos aparece a metáfora do sono (1Co $15,6.18 .20 .51$; 1 Ts $4,13-18 ; 5,9-10)$, certamente retomada de Dn $12,2^{20}$; por vezes existe a idéia de que os mortos estão conscientes no Sheol (Hades), podendo até mesmo conversar, como acontece na parábola do rico e Lázaro em Lc 16,19-31, havendo zonas separadas para justos e injustos. Este último texto deixa transparecer também a idéia de que felicidade e miséria no pós-morte são fruto da postura em vida, idéia que, como vimos, já estava presente em Zoroastro e Hesíodo.

Essas diferentes tradições presentes no corpo do Novo Testamento permitem aferir que não havia uma idéia unívoca de como se efetuaria a própria ressurreição, ao contrário do que postula, por exemplo, Oscar Cullmann, supondo haver uma mesma visão acerca do pós-morte entre os judeus, estando os cristãos em continuidade com essa visão ${ }^{21}$. Na própria escatologia judaica parece existir a idéia de que algumas pessoas especiais teriam uma assunção imediata aos céus, pessoas essas que morreram em perseguição religiosa, os mártires, conforme verificado acima. Já em 1En 22 e 4Esd 7 as recompensas da nova vida eram experimentadas, pelo menos em parte, num estado intermediário ${ }^{22}$.

Dessa forma, é razoável supor que nem todos os grupos judaicos no judaísmo tardio pensavam a mesma escatologia, muito menos uma existência sombria no Sheol como destino final de todos os homens. Pode-se então afirmar o mesmo sobre a escatologia cristã primitiva: não havia uma unicidade de pensamento, em continuidade com a escatologia judaica. Pode-se pensar ainda que as mesmas influências persas e helênicas que se deram na escatologia judaica tardia passaram ao cristianismo, mesmo que em menor grau, o que também não desmerece a contribuição de cada grupo

\footnotetext{
${ }^{19}$ Cf., por exemplo, 2Co 5,6-10; Fp 1,12-26; 1Ts 4,14 e Lc 23,43. Neste último texto, Jesus afirma ao ladrão arrependido: "Em verdade te digo que hoje estarás comigo no paraíso".

${ }^{20}$ Cf. SEGAL, Alan F. Life after Death: a History of the Afterlife in the Religious of the West, p.403.

${ }^{21}$ Cf. o clássico artigo, em sua terceira publicação: CULLMANN, Oscar. Immortality of the Soul or Resurrection of the Dead? In: STENDAHL, Krister (Ed.). Immortality and Resurrection, Death in the Western World: Two Conflicting Currents of Thought, p. 9-47. Cf. a versão portuguesa desse texto em: CULLMANN, Oscar. Das origens do evangelho à formação da teologia cristã, p. 183-210. Cf. também a crítica em NICKELSBURG, George W. Resurrection, Immortality and Eternal Life in Intertestamental Judaism and Early Christianity, p. 219-223.

${ }^{22}$ NICKELSBURG, George W. Op. cit., p. 174.
} 
em sua realidade existencial.

A ênfase cristã na ressurreição se dá a partir do martírio do Cristo. Nesse sentido, não deixa de estar em continuidade com a tradição de martírio presente em 2 Macabeus e em Dn 12. A diferença é que para os cristãos a ressurreição de Jesus ocorre antes do grande julgamento, tornando-se paradigmática para a futura ressurreição dos fiéis. A única exceção a esse quadro geral se dá em Mt 27, 51-53.

De fato, o grupo dos seguidores de Jesus viu na sua morte e na crença em sua ressurreição a consumação da história: os eventos da Páscoa foram vistos como o começo da concretização dos eventos preconizados pelos profetas hebreus e, mais detidamente, pelo visionário Daniel, sendo Jesus o Filho do Homem que retornaria para punir os ímpios e trazer vida eterna aos justos. Assim, muitos grupos cristãos interpretaram o evento de Cristo a partir do cenário apocalíptico descrito por Daniel.

\section{A ressurreição corporal na tradição paulina}

Além da tradição sinótica, outra tendência importante com relação à ressurreição se dá na tradição paulina, expressa em 1Co 15, talvez mais antiga que a sinótica (o apóstolo afirma aos coríntios que "vos entreguei o que também recebi", em 15,3a). Paulo apresenta uma expectativa futura que, diferentemente dos evangelistas, independe da tradição do túmulo vazio $^{23}$. Para ele, a crença num futuro pessoal para além da morte física dita as regras para a fé cristã ${ }^{24}$. Sua preocupação tangencia não o reino messiânico material, humano, mas sim o escatológico. Neste capítulo, apesar de utilizar categorias helênicas em suas descrições, o apóstolo expõe seu pensamento acerca da ressurreição distanciando-se da idéia platônica de que o corpo estava destinado à destruição ${ }^{25}$. Ele afirma que o corpo so-

\footnotetext{
${ }^{23}$ Albrecht Oepke assinala que "embora Paulo aceite o túmulo vazio (1Co 15,47-50), ele não pensa no corpo do Senhor ressuscitado em termos materiais, mas sim como o $\sigma \tilde{\omega} \mu \alpha$

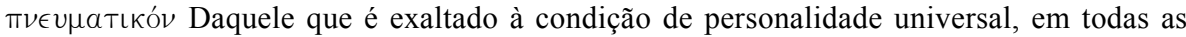
coisas, e especialmente na Igreja $(\mathrm{Cl} 1,18 \mathrm{~s})$. Por outro lado, interesses apologéticos direcionaram a tradição evangélica pós-canônica para um sentido mais material (Lc 24,39s; At 10,41 ; Jo 20,25s). Contudo, as características espirituais não estão ausentes (Jo 20,17.19.26), e talvez uma distinção deva ser feita entre o Senhor imediatamente ressuscitado e o Senhor exaltado" (cf. OEPKE, Albrecht. Verbete $\epsilon^{\prime} \gamma \epsilon i \rho \omega$. In: KITTEL, Gerhard; FRIEDRICH, Gerhard (Ed.). Theological Dictionary of the New Testament II, p. 335).

24 “Mas se não há ressurreição de mortos, também Cristo não foi ressuscitado. E, se Cristo não foi ressuscitado, logo é vã a nossa pregação, e também é vã a vossa fé" (1Co 15,13-14). ${ }^{25}$ Cf. SEGAL, Alan F. Life after Death: a History of the Afterlife in the Religious of the West, p. 422-423.
} 
breviverá à morte, ressuscitado em glória e perfeição por Deus, assim como foi o corpo de Jesus. Portanto, o apóstolo ensina não a destruição do corpo, mas a sua transformação, destinada não somente aos que já morreram, mas também aos que estiverem vivos na parousía (1Co 15,51-53; 1Ts $4,13-18)^{26}$. É possível que os que negavam a ressurreição em Corinto (mencionados pelo apóstolo em 1Co 15,12) tinham sido rechaçados pelo materialismo presente na expectativa judaica ${ }^{27}$.

$\mathrm{Na}$ antropologia paulina de $1 \mathrm{Co} 15,35-53$, tanto a vida no seu sentido mais básico (psíquica) quanto a vida espiritual (pneumática) eram corpóreas; entretanto, aparece certa tensão em sua concepção de homem ${ }^{28}$. Nos versos 44 e 55, o corpo físico (sôma psychikón) é o corpo ordinário (carne e alma), ao passo que o corpo espiritual (sôma pneumatikón) é o corpo ordinário transformado pelo espírito. Este corpo transformado é o corpo ressuscitado (egeíretai). Dessa forma, com essas expressões antagônicas, o apóstolo ensina uma espécie de antes e depois da parousía.

Nessa antítese paulina, as concepções helenísticas vêm de encontro à antropologia judaica; a concepção de Paulo lembra a antítese platônica mundo inteligível ( $v$ ov $\zeta)$ e mundo sensível; entretanto, "à semelhança dos judeus alexandrinos (Sabedoria, Fílon), Paulo substituirá ordinariamente o $\nu$ oũ s pelo $\pi \nu \in \tilde{v}$. O sentido da antítese platônica está, pois, profundamente modificado, tornando-se uma oposição de ordem filosófica, ordem religiosa"29. Para Segal, nesse caso, Paulo utiliza o discurso de transformação

\footnotetext{
${ }^{26}$ O texto de 1Co 15,51-53 registra: "Eis aqui vos digo um mistério: Nem todos dormiremos mas todos seremos transformados, num momento, num abrir e fechar de olhos, ao som da última trombeta; porque a trombeta soará, e os mortos serão ressuscitados incorruptíveis, e nós seremos transformados. Porque é necessário que isto que é corruptível se revista da incorruptibilidade e que isto que é mortal se revista da imortalidade (athanasían)". A última palavra do verso é, a exemplo de $\mathrm{Sb} 3,4$, imortalidade.

${ }^{27}$ Cf. OEPKE, Albrecht. Resurrection in the NT. In: KITTEL, Gerhard; FRIEDRICH, Gerhard (Ed.). Theological Dictionary of the New Testament I, p. 371.

28 1Co 15,44-46 registra: "Semeia-se corpo fisico (sôma psychikón), é ressuscitado (egeíretai) corpo espiritual (sôma pneumatikón). Se há corpo físico, há também corpo espiritual. Assim também está escrito: $\mathrm{O}$ primeiro homem, Adão, tornou-se alma vivente (psychên zôsav); o último Adão, espirito vivificante (pneûma zốopoioûn). Mas não é primeiro o espiritual, senão o físico; depois o espiritual". Observa-se que o apóstolo contrapõe os adjetivos psychikós e pneumatikós e os substantivos psychê e pneûma. O termo pneûma, para Paulo, "não é sinônimo de imaterial, mas significa força, luz, santidade, alguma coisa proveniente do mundo do divino", não havendo para ele, assim, nenhuma contradição na expressão "corpo espiritual" (cf. NELIS, J. Verbete Ressurreição. In: VAN DEN BORN, A. (Ed.). Dicionário enciclopédico da Bíblia, p. 1307).

${ }^{29}$ CERFAUX, Lucien. Cristo na teologia de Paulo, p. 218. Para Fílon, o corpo é apenas um santuário que abriga a "imagem divina", ou seja, a "alma racional", o qual recebe o $\pi \nu \in \tilde{v} \mu a$. Na concepção paulina, o corpo, animado pela $\psi v \chi \eta$, forma o "corpo vivo", ou
} 
espiritual para evangelizar os gentios ${ }^{30}$; ou seja, o apóstolo estaria usando categorias helênicas para argumentação contra o conceito grego de imortalidade e, a partir dessas mesmas categorias, sistematizando o seu próprio conceito (evangélico-cristão).

Texto mais antigo que o de 1 Co 15 é 1Ts 4,13-18, no qual o apóstolo trata da questão "dos que dormem" (v. 13) tendo em vista o consolo da comunidade de Tessalônica. Baseando sua argumentação na ressurreição de Cristo como fonte e princípio para a ressurreição também dos cristãos em geral, o apóstolo afirma que, por ocasião da parousía, os mortos cristãos terão prioridade na ressurreição, encontrando-se com Cristo nos ares. Posteriormente os vivos (entre os quais o apóstolo se inclui) serão arrebatados e também encontrarão o Mestre nas nuvens. Não se fala em julgamento final e nem na ressurreição dos ímpios, deixando implícito que estes continuarão mortos pela eternidade. O apóstolo embasa seu texto em uma "palavra que recebeu do Senhor", certamente pela tradição oral, visto que não se encontra no NT o registro desse ensinamento por parte do Cristo.

Percebe-se, assim, uma certa modificação no pensamento do apóstolo acerca da questão da parousía e conseqüente ressurreição corporal.

\section{Conclusão}

Seja uma ressurreição com ênfase mais no próprio corpo físico seja num corpo transformado, espiritual, o evento da ressurreição está presente em todas as tradições que compunham a escatologia da Igreja primitiva ${ }^{31}$. Embora não sendo uma idéia originalmente judaica ou cristã, a ressurreição deu um caráter particular à escatologia judaica, sendo tal expectativa assimilada pelo cristianismo nascente. Este lhe deu novo significado a partir da

seja, a própria pessoa; para que o homem seja espiritual, esse "corpo vivo" deve ser espiritualizado (ibidem, p. 220).

${ }^{30}$ SEGAL, Alan F. Life after Death: a History of the Afterlife in the Religious of the West, p.402.

${ }^{31}$ Alguns estudiosos hoje acreditam, por motivos diversos, que a narrativa da ressurreição constitui uma metáfora, e não um evento histórico em sentido estrito (cf. como representante dessa corrente CROSSAN, John Dominic. Resurrection of Jesus in its Jewish Context. In: STEWART, Robert (Ed.). The Resurrection of Jesus: John Dominic Crossan and N. T. Wright in Dialogue, p. 46-47). Já N. T. Wright está entre os que postulam uma ressurreição literal em termos históricos (cf. WRIGHT, Nicholas Thomas. The Resurrection of the Son of God, p. 321, 686-696 e 709-710). Já Sanders está entre os que reconhecem o fato, mas sem poder prová-lo: "Que os seguidores de Jesus (e depois Paulo) tiveram experiências de ressurreição é, em meu julgamento, um fato. Qual realidade deu levante às experiências eu não sei”" (cf. SANDERS, E. P. The Historical Figure of Jesus, p. 280). 
ressurreição de seu fundador, o Messias cristão Jesus Cristo: "A ressurreição de Cristo dava o sinal da parusia e da ressurreição geral dos mortos. Dificilmente se opunham a ressurreição de Cristo e a dos outros mortos" ${ }^{132}$. Wright chega a definir o cristianismo primitivo em três categorias justapostas: um movimento do Reino de Deus, um movimento messiânico e um movimento de ressurreição ${ }^{33}$. É nesta última etapa que, certamente, a influência paulina se fez sentir com mais vigor.

Dionísio Oliveira Soares

Bacharel e Licenciado em Letras Clássicas pela UFRJ, Mestre e doutorando em Teologia pela PUC-RJ, Docente da Faculdade Batista do Rio de Janeiro (FABAT). e-mail: dionisiosoares2001@yahoo.com.br

\section{Referências Bibliográficas}

BULTMANN, Rudolf. A History of the Synoptic Tradition. New York: Harper \& Row, 1963. p.456.

CERFAUX, Lucien. Cristo na teologia de Paulo. Tradução Monjas Beneditinas da Abadia de Santa Maria. São Paulo: Teológica, 2003. p.443

CULLMANN, Oscar. Das origens do evangelho à formação da teologia cristã. Tradução de Daniel Costa. São Paulo: Novo Século, 2000. p.224

DAVIES, W. D.; FINKELSTEIN, Louis (Ed.). The Cambridge History of Judaism: Introduction; the Persian Period. 7. imp. Cambridge: Cambridge University Press, 2004. p.461. v. 1.

JEREMIAS, Joachim. Teologia do Novo Testamento. Tradução de João R. Costa. 2. ed. São Paulo: Teológica, 2004. p.504.

JOSEPHUS. Jewish Antiquities, Books 18-19. Harvard: Harvard University Press, 1965. p.448. (Loeb Classical Library).

. The Jewish War, Books III-IV. Harvard: Harvard University Press, 1927. p.368. (Loeb Classical Library).

KITTEL, Gerhard; FRIEDRICH, Gerhard (Ed.). Theological Dictionary of the New Testament. Michigan: Eerdmans, 1977. vol. I-II.

\footnotetext{
${ }^{32}$ CERFAUX, Lucien. O cristão na teologia de Paulo, p. 55.

${ }^{33}$ Cf. WRIGHT, N. T. Christian Origins and the Resurrection of Jesus: the Resurrection of Jesus as a Historical Problem. In: BRYAN, Christopher (Ed.). Sewanee Theological Review 41.2, 1998, p. 23-38.
} 
LONGENECKER, Richard N. (Ed.). Life in the Face of Death: the Resurrection Message of the New Testament. Michigan: Eerdmans, 1998. p.314.

MÜLLER, Friedrich Max. The Eschatology of the Avesta. In: Theosophy or Psychological Religion. Montana: Kessinger, 2007. p.177-207.

NICKELSBURG, George W. E. Resurrection, Immortality, and Eternal Life in Intertestamental Judaism and Early Christianity. Expanded ed. Massachusetts: Harvard University Press, 2006. p.366. (Harvard Theological Studies, 56).

RUSSELL, David Syme. The Method and Message of Jewish Apocalyptic. Philadelphia: The Westminster Press, 1964. p.464.

SANDERS, E. P. The Historical Figure of Jesus. London: Penguin Books, 1996. p.352.

SEGAL, Alan F. Life after Death: a History of the Afterlife in the Religions of the West. New York: Doubleday, 2004. p.866.

Heavenly Ascent in Hellenistic Judaism, Early Christianity and their Environment. Aufsteig und Niedergang der Romischen Welt II.23.2, 1980. Massachusetts: Boston University, p.1333-1394.

SETZER, Claudia. Resurrection of the Dead as Symbol and Strategy. Journal of the American Academy of Religion 69.1, 2001. Cary, North Carolina: Oxford University Press, p.65-102.

. Resurrection of the Body in Early Judaism and Early Christianity: Doctrine, Community and Self-Definition. Leiden: Brill, 2005. P.190.

STENDAHL, Krister (Ed.). Immortality and Resurrection, Death in the Western World: Two Conflicting Currents of Thought. New York: Macmillan, 1965. P.333.

STEWART, Robert (Ed.). The Resurrection of Jesus: John Dominic Crossan and N. T. Wright in Dialogue. Minneapolis: Fortress Press, 2006. p.220.

VAN DEN BORN, A. (Ed.). Dicionário enciclopédico da Bíblia. Tradução de Frederico Stein. 3. ed. Lisboa: Centro do Livro Brasileiro Limitada; Petrópolis: Vozes, 1971.

WRIGHT, Nicholas Thomas. The Resurrection of the Son of God. Minneapolis: Augsburg Fortress, 2003. p.740. 